\title{
2009: the year of innovations-third innovation
}

\author{
Max Aebi
}

Received: 23 July 2009/Published online: 4 August 2009

(C) Springer-Verlag 2009

After having introduced into the European Spine Journal a Chinese Section with its own small sub-editorial board and the concept of "Grand Rounds" (see issues 3, 5, and 7, Vol. 18, 2009) it is my pleasure to introduce the newest product of the European Spine Journal and EuroSpine-The Spine Society of Europe: the Open Operating Theatre (OOT).

The European Spine Journal is used as a platform, where films of surgical techniques and procedures are available. These are films for the subscribers of the European Spine Journal, which are available online. These surgical films are all edited according to the same script and shall be considered as standardized teaching and learning material for surgeons in training and for established surgeons as refresher. The films are presented in the European Spine Journal in the form of structured printed abstracts, which will be indexed like any other article in the journal, and provide to the authors the impact factor (IF) of the journal and to the subscribers ultimately CME points (in preparation). All the classical procedures in spine surgery shall finally be available in a video library in the OOT, and shall all be free for subscribers. The structured script shall guarantee the educational value of the material. The plan is that at least three to four times per year an issue contains 4 abstracts for corresponding films in the OOT. In the abstract it is indicated on which web address the film can be accessed with the subscribers user name and password.

M. Aebi $(\bowtie)$

Institute for Evaluative Research in Orthopaedic Surgery, MEM Research Center for Orthopaedic Surgery,

University of Bern, Stauffacherstrasse 78,

3014 Bern, Switzerland

e-mail: max.aebi@MEMcenter.unibe.ch

URL: http://www.MEMcenter.unibe.ch
It is the goal of the video library to present all the regular classical surgical techniques not only from one surgeon, but also ultimately from different surgeons just like we can listen to a classical piece of music with different conductors and soloists.

In addition to those regular surgical videos of the OOT, the European Spine Journal is also creating films according to the same principles about new technologies and techniques arising in the spinal market. New techniques and technologies may be presented once or twice a year in the form of a special OOT video supplement, which is sponsored by the MedTech Industry. The idea is to teach new techniques and technologies according to the same standardized rules like the regular films in order to make them free from industry influence and bias. This will give to the industrial partner the opportunity to offer to the spinal community and their clients European Spine Journal-accredited teaching and learning material and not just advertisement material. This will definitely add value to the OOT on one side and to the industrial partner on the other side by acquiring a generally accredited teaching portfolio.

The films, which are available and shown on the video web-platform of the European Spine Journal (Springer Publisher) may ultimately also be acquired in the free market.

The echo of surgeons, who are willing to contribute with their expertise and accept the extra work of producing such films has been overwhelming, and the European Spine Journal is now going to tap on this resource in the next years to build up a complete audio-visual learning and teaching platform. If anybody of the subscribers and readers of the European Spine Journal has ideas how to improve the quality or expand the initiative or to contribute themselves, do not hesitate to contact me. 
In this issue we will have the first series of four video films of the OOT. As these first products may not yet be the full quality of what is intended, the films in the next issues will certainly be. Starting with the next issue all the films will specifically be produced for the OOT, whereas the first series has been produced from existing films.
I hope you appreciate and enjoy this new service and product of the European Spine Journal.

M. Aebi

Editor-in-Chief 